J. Pijar MIPA, Vol. VI No.1, Maret : 18 - 23

ISSN 1907-1744

\title{
NYERI HAID, PENYEBAB, DAN PENANGGULANGANNYA
}

\author{
Kusmiyati \\ Program Studi Pendidikan Biologi, Jurusan PMIPA FKIP Universitas Mataram \\ Jl. Majapahit 62 Mataram, 83125
}

\begin{abstract}
Abstrak : Haid atau menstruasi merupakan pelepasan dinding endometrium disertai darah. Nyeri sering menyertai kejadian menstruasi, sebagai hasil kontraksi kuat miometrium yang terjadi menjelang dan selama menstruasi Faktor penyebab nyeri haid bermacam-macam, antara lain faktor endokrin, kejiwaan dan faktor lain yang terkait dengan alat reproduksi. Nyeri dapat terjadi karena sekresi prostaglandin yang berlebih. Umumnya perempuan yang mengalami nyeri haid tidak terlalu memperhatikan atau tidak merawat dengan khusus, karena kejadiannya sudah biasa, namun ada pula yang merasa sangat tidak nyaman. Nyeri haid dapat dikurangi dengan obat anti peradangan atau obat yang menghambat biosintesis prostaglandin, dan dengan tanpa obat seperti pijat, kompres hangat, mendengarkan musik, menonton televisi atau melatih pernafasan.
\end{abstract}

Kata kunci : Haid

\section{MENTRUAL CRAMPS, CAUSE AND ALLIVIATE}

Abstrac : Menstruation is the release of endometrium wall accompanied by blood. Menstrual cramps are the results of strong myometrial contraction that occur just before and during menstruation period. The causes of menstrual cramps could be endocrine, psychological and other factors related to reproduction organ. The cramps may be due to excessive prostaglandin secretion. Generally, women ignore the menstrual cramps because it is the monthly routine, but others feel extremely uncomfortable Menstrual cramp (painful) can be reduced by taking anti-inflamantory drugs or drugs which inhibit prostaglandin biosynthesis or non medicinal practices like massase, warm compress, listening to music, watching television, or breathing relaxation.

Key word : Mentrual

\section{PENDAHULUAN}

Perempuan usia remaja hingga dewasa selalu mengalami peristiwa menstruasi atau haid. Haid merupakan siklus bulanan yang melibatkan faktor hormonal pada ovarium dan uterus. Menstruasi biasanya dimulai antara umur 10-16 tahun, sampai mencapai usia $45-50$ tahun. Selain faktor hormonal menstruai juga tergantung pada faktor kesehatan dan status nutrisi. Pengaruh hormon menimbulkan perubahan pada alat reproduksi, yang sering menimbulkan ketegangan, perasaan tidak enak pada daerah perut bawah, payudara terasa menjadi tegang atau sedikit membengkak dan nyeri, bahkan menimbulkan perasaan lain yang berbeda - beda persepsinya pada setiap orang. Sehubungan dengan itu, tidak jarang perempuan yang mengalami menstruasi disertai dengan nyeri, yang sering terjadi sebelum, atau selama haid .

Nyeri haid biasa disebut dismenore, biasanya sangat menyiksa bagi perempuan. Banyak diantara mereka tidak bisa bangun dari tempat tidur atau mengalami kesulitan berjalan, tidak jarang yang mengalami penderitaan, sehingga tidak dapat mengerjakan apapun. Remaja putri yang mengalami nyeri haid, biasanya harus beristirahat, sehingga sangat mempengaruhi aktivitasnya sehari-hari dan berdampak pada kinerja atau produktivitas remaja tersebut.

Menurunkan atau menghilangkan nyeri haid dapat dilakukan dengan cara farmakologis dan non farmakologis. Cara farmakologi, misalnya dengan menggunakan obatobatan analgesik, sedangkan cara non farmakologis merupakan proses fisiologis yang lebih aman digunakan, seperti penggunaan kompres hangat atau dingin, mendengarkan musik dan sebagainya. Kedua cara bertujuan untuk meningkatkan relaksasi otot-otot dan mengurangi nyeri akibat kekakuan otot. Berdasar hal tersebut dalam tulisan ini akan dibahas tentang haid atau menstruasi, tinjauan tentang nyeri haid dan penyebabnya, serta penanggulangan nyeri haid.

\section{PEMBAHASAN}

\subsection{Haid atau Menstruasi}

Setiap perempuan yang telah mengalami pubertas, sehat, tidak sedang hamil dan tidak menopause akan mendapat menstruasi secara teratur setiap bulannya. Menstruasi merupakan perubahan fisiologi tubuh perempuan yang terjadi secara berkala, dipengaruhi oleh hormon estrogen dan progesteron. Menstruasi mengacu pada pengeluaran darah disertai pelepasan (deskuamasi) dinding endometrium. Menurut [5], menstruasi merupakan pengurangan mendadak hormon estrogen dan progesteron pada ovarium, yang berhubungan dengan siklus endometrium uterus.

Perubahan berirama pada ovarium dan uterus dinamakan siklus seksual atau biasa disebut siklus menstruasi. Rata-rata panjang siklus seksual pada perempuan adalah 28 hari. Lamanya haid berbeda-beda antara 2-8 hari, dengan rata-rata 4-6 hari. Perubahan ovarium selama siklus seksual seluruhnya tergantung pada hormon gonadotropin yang disekresi kelenjar hipofisis anterior, meliputi hormon perangsang folikel atau FSH (Follicel Stimulating Hormone ) dan hormon luteinisasi atau LH ( Luteinizing Hormone).

Ovarium merupakan organ utama perempuan, karena dalam ovarium terjadi proses pembentukan sel telur melalui proses oogenesis. Ovarium mengandung banyak folikel primordial yang akan mengalami pertumbuhan hingga terjadi ovulasi. Sebelum pubertas, ovarium masih 
Nyeri Haid, Penyebab, dan Penanggulangannya..... (Kusmiyati)

dalam keadaan istirahat, tetapi ketika masa pubertas hipofisis anterior mulai mensekresi hormon gonadotropin yaitu FSH dan LH, folikel-folikel mengalami pertumbuhan. Adanya hormon FSH dan LH, maka beberapa folikel primordial akan tumbuh dan hanya satu ovum yang masak dan akan dikeluarkan dari ovarium, sedang yang lain mengalami atresia

Proses atresia, menurut [5] penting agar memungkinkan hanya satu dari folikel tumbuh cukup besar untuk ovulasi. Lebih lanjut dijelaskan, penyebab atresia tidak diketahui, tetapi dapat dijelaskan sebagai berikut: satu folkel yang berkembang lebih pesat mensekresi lebih banyak estrogen, sehingga menimbulkan penghambatan umpan balik FSH. Kekurangan hormon ini tidak menghambat folikel yang paling besar, karena estrogen mempunyai efek merangsang diri sendiri yang menyebabkan folikel terus tumbuh, sedangkan pada folikel yang kurang berkembang, kekurangan FSH menyebabkan folikel berhenti berkembang dan mengalami involusi ( atresia).

Siklus menstruasi meliputi siklus ovarium ( terdiri dari fase folikular dan fase luteal ) dan siklus endometrium yang meliputi fase proliferasi, fase sekresi dan fase menstruasi [18]. Fase folikuler, disebut demikian karena pada fase ini terjadi pertumbuhan folikel di dalam ovarium. Fase folikuler dimulai dari hari ke-1 sampai sesaat sebelum kadar LH meningkat dan terjadi pelepasan ovum. Pada fase ini hanya satu folikel yang terus berkembang membentuk folikel Graff dengan antrum yang besar dan ovum dikelilingi dua lapis sel, lapisan dalam berupa sel granulosa, yang mensintesis progesteron dan disekresi ke dalam cairan folikuler. Progesteron ini sebagai prekursor pada sintesis estrogen oleh sel teka interna. Lebih lanjut dikatakan, pada folikel ini oosit primer mengalami kematangan, dan pada waktu yang sama, folikel yang sedang berkembang mensekresi estrogen lebih banyak. Meningkatnya kadar estrogen menyebabkan pelepasan LHRH melalui umpan balik positif.

Fase ovulatoir dimulai ketika kadar LH meningkat dan pada fase ini dilepaskan ovum. Pada saat ovulasi ini beberapa perempuan merasakan nyeri tumpul pada perut bagian bawahnya [12], sedangkan [18] tidak memilah fase pelepasan ovum sebagai fase ovulatori, tetapi dimasukkan sebagai fase luteal. Setelah oosit lepas dari folikel Graff, lapisan granulosa menjadi banyak mengandung pembuluh darah dan sangat terluteinisasi, berubah menjadi korpus luteum, sehingga disebut sebagai fase luteal. Korpus luteum menghasilkan hormon estrogen dan progesteron. Kadar estrogen yang tinggi dalam darah menghambat produksi FSH, sehingga tidak ada folikel yang dirangsang menjadi folikel Graff. Progesteron menyebabkan suhu tubuh sedikit meningkat, oleh karena itu peningkatan suhu digunakan untuk memperkirakan terjadinya ovulasi Setelah 14 hari, apabila telur tidak dibuahi, korpus luteum akan hancur (membentuk korpus albicans), sehingga terjadi penurunan kadar estrogen dan progesteron serta dihasilkannya kembali FSH dan siklus yang baru akan dimulai..

Siklus endometrium seperti telah disebutkan di atas meliputi fase proliferasi, fase sekresi dan fase menstruasi.
Fase proliferasi, segera setelah menstruasi, endometrium dalam keadaan tipis dan dalam stadium istirahat, yang berlangsung kira-kira 5 hari. Kadar estrogen yang meningkat dari folikel yang berkembang akan merangsang stroma endometrium untuk mulai tumbuh dan menebal, kelenjar-kelenjar menjadi hipertropi dan berproliferasi dan pembuluh darah menjadi banyak sekali. Kelenjarkelenjar dan stroma berkembang sama cepatnya. Kelenjar makin bertambah panjang tetapi tetap lurus dan berbentuk tubulus. Lamanya fase proliferasi sangat berbeda-beda pada tiap orang, berakhir pada saat terjadinya ovulasi.

Fase sekresi, setelah ovulasi di bawah pengaruh progesteron yang meningkat dan terus diproduksinya estrogen oleh korpus luteum, endometrium semakin menebal dan menjadi seperti beludru, dilengkapi dengan jaringan yang memungkinkan tumbuh dan berkembangnya janin apabila dibuahi. Apabila tidak dibuahi maka jaringan tersebut akan luruh.

Fase menstruasi, berawal dari hari pertama menstruasi sampai hari ke lima. Proses menstruasi terjadi karena penurunan kadar estrogen dan progesteron dalam darah, sebagai akibat tidak berfungsinya korpus luteum. Berkurangnya bahkan tidak adanya dua hormon tersebut, endometrium hancur dan mulai luruh. Menstruasi merupakan peluruhan endometrium uterus yang terdiri dari jaringan dan darah.

Berdasarkan penjelasan tersebut, dapat dikatakan bahwa peristiwa yang terjadi pada ovarium dan uterus selama siklus menstruasi tidak dapat dipisahkan satu sama lain, sebab ketika di ovarium terjadi pematangan folikel dihasilkan estrogen dan progesteron yang semakin meningkat. Meningkatnya kedua hormon tersebut, dinding uterus menjadi tebal, dan banyak pembuluh darah, sebagai persiapan apabila ovum dibuahi. Jika tidak terjadi pembuahan, kadar estrogen dan progesteron menurun akibat korpus luteum rusak, dengan menurunnya kedua hormon tersebut, endometrium meluruh dan FSH meningkat sehingga ovarium mempersiapkan folikel kembali.

\subsection{Nyeri haid dan penyebabnya}

Sebelum di bahas nyeri haid, perlu diketahui tentang nyeri secara umum. Nyeri merupakan kondisi berupa perasaan yang tidak menyenangkan dan bersifat sangat subyektif [7], sedangkan [5] menyebutkan, nyeri adalah suatu mekanisme protektif bagi tubuh, timbul jika jaringan sedang di rusak, menyebabkan individu bereaksi untuk menghilangkan rangsang nyeri tersebut. Berdasarkan kedua pendapat tersebut dapat diartikan bahwa nyeri adalah perasaan tidak nyaman, sebagai usaha proteksi tubuh ketika terjadi stimulus yang merugikan.

Penyebab nyeri dibedakan menjadi penyebab fisik dan psikis. Penyebab fisik antara lain berupa trauma dan peradangan nyeri, sedangkan penyebab psikis akibat trauma psikologis dan pengaruhnya terhadap fisik. Reseptor nyeri disebut nociseptor, reseptor nyeri di kulit dan jaringan lain merupakan ujung saraf bebas, yang tersebar dalam lapisan superfisial kulit, dan jaringan visera seperti pada periosteum, permukaan sendi, dinding arteri dan sebagainya. Ketika suatu jaringan mengalami cedera atau kerusakan, mengakibatkan dilepaskannya bahanbahan yang dapat menstimulus reseptor nyeri seperti 
histamin, prostaglandin, atau substansi $\mathrm{P}$ yang akan mengakibatkan respon nyeri. Seperti pendapat [5], stimulus yang mengeksitasi reseptor nyeri dapat berupa mekanis, kimia dan suhu. Lebih lanjut dijelaskan bahwa beberapa serat nyeri hampir seluruhnya terangsang oleh stres mekanis berlebihan atau kerusakan mekanis pada jaringan disebut sebagai reseptor nyeri mekanosensitif. Yang lain sensitif terhadap panas dan dingin yang ekstrim atau disebut reseptor nyeri termosensitif, dan lainnya sensitif terhadap zat kimia seperti histamin, ion kalium, prostaglandin, asetilkolin dan enzim proteolitik, sehingga disebut reseptor nyeri kemosensitif. Prostaglandin dapat menyebabkan stimulasi serat saraf nyeri yang ekstrim tanpa harus merusaknya.

Fisiologi nyeri, [5] menjelaskan bahwa rangsang nyeri yang tiba-tiba memberikan sensasi ganda, yaitu nyeri tertusuk yang cepat diikuti sensasi nyeri terbakar yang lambat. Lintasan nyeri memasuki medula spinalis melalui akar dorsal, dan berakhir pada kornu dorsalis substansi grisea. Impuls naik ke otak melalui traktus spinotalamikus anterolateralis. Ketika lintasan masuk dalam otak, terpisah menjadi dua lintasan, nyeri ditusuk dan nyeri terbakar. Nyeri tertusuk dihantarkan ke talamus dan kortek sensori somatik. Lintasan nyeri terbakar dan pegal berakhir pada daerah retikularis batang otak dan nukleus intralaminar talamus, yang menghantarkan impuls ke seluruh bagian otak termasuk hipotalamus. Jadi, karena serabut nyeri terbakar dan pegal merangsang sistem pengaktivasi retikularis, maka mempunyai efek sangat kuat dalam menggiatkan seluruh sistem saraf.

Nyeri menyebabkan reaksi refleks motorik dan reaksi psikis. Impuls nyeri memasuki substansi grisea medula spinalis dapat langsung memulai refleks penarikan diri yang menjauhkan tubuh dari rangsang berbahaya. Reaksi psikis meliputi semua aspek nyeri seperti sedih, menangis, depresi, mual, muntah. Reaksi ini sangat bervariasi antara satu orang dengan orang lain.

Berdasarkan lokasi, [16] membedakan nyeri menjadi beberapa macam antara lain: a). nyeri kutaneus atau superfisial, yaitu nyeri yang dirasakan di kulit atau jaringan subkutis, misalnya nyeri ketika tertusuk jarum atau lutut lecet; b). nyeri somatik yaitu nyeri dalam yang berasal dari tulang dan sendi, tendon, otot rangka, dan pembuluh darah; c). nyeri viseral, yaitu nyeri dirongga abdomen atau torak; d). Nyeri alih adalah nyeri yang timbul akibat adanya nyeri viseral yang menjalar / dialihkan ke organ lain, sehingga dirasakan nyeri pada beberapa tempat atau lokasi.. Lebih lanjut dijelaskan, berdasarkan lama / durasinya dibedakan menjadi nyeri akut dan nyeri kronis. Nyeri akut adalah nyeri yang terjadi dalam waktu 1 detik sampai 6 bulan, sedangkan nyeri kronis adalah nyeri yang terjadi dalam waktu lebih dari 6 bulan.

Penyebab nyeri viseral, [5] menyebutkan bahwa rangsang apapun yang merangsang ujung saraf nyeri di daerah visera menyebabkan nyeri viseral. Rangsang tersebut berupa iskemik jaringan viseral, spasme otot polos suatu visera berongga, kerusakan kimia pada permukaan visera, distensi suatu visera berongga atau peregangan ligamen. Hampir semua impuls nyeri viseral yang berasal dari rongga dada dan perut dihantarkan melalui serabut saraf sensoris yang berjalan dalam saraf simpatis. Nyeri visera yang spastik terjadi dalam bentuk kejang, nyeri bertambah hebat dan kemudian reda, proses nyeri ini terjadi secara ritmik sekali tiap beberapa menit. Nyeri kejang sering terjadi pada gastroenteritis, konstipasi, menstruasi, partus, penyakit kandung empedu atau obstruksi ureter.

Nyeri aferen parietal dan viseral dapat dihantarkan dari uterus. Nyeri kejang perut bagian bawah pada haid dihantarkan melalui aferen simpatis, suatu operasi untuk memotong nervus hipogastrikus diantara pleksus hipogastrikus dan uterus akan mengurangi nyeri pada banyak kasus. Sebaliknya, lesi uterus yang menyebar ke sekitar uterus atau lesi tuba falopi dan ligamentum lutum, biasanya menyebabkan nyeri di punggung atau pinggang bawah. Nyeri ini dihantarkan melalui serabut saraf parietal dan bersifat lebih tajam, menyerupai nyeri kejang tersebar pada dismenore sejati.

Nyeri haid atau dismenore menurut [2], adalah nyeri yang timbul akibat kontraksi disritmik miometrium yang menampilkan satu atau lebih gejala, mulai dari nyeri ringan sampai berat dan disertai berbagai tanda, mulai dari mual, muntah, diare, pusing, nyeri kepala, sampai pingsan. [10] menambahkan bahwa nyeri haid adalah nyeri menjelang atau selama haid, sehingga mengakibatkan gangguan aktivitas dan harus istirahat, yang diikuti dengan rasa mual, sakit kepala, mau pingsan dan lekas marah, sedangkan [18], menyebutkan bahwa dismenore adalah nyeri selama menstruasi yang disebabkan oleh kejang otot uterus..Berdasarkan ketiga pendapat tersebut dapat diartikan bahwa nyeri haid adalah nyeri menjelang atau selama haid yang terjadi karena kontraksi otot uterus, yang sering diikuti dengan gejala lain seperti mual,muntah, lekas marah, pusing dan sebagainya.

Beberapa ahli memilah nyeri haid ( dismenore) berbeda-beda, seperti [1], membagi nyeri haid menjadi dismenore primer dan dismenore sekunder. Dismenore primer adalah nyeri haid tanpa kelainan pada alat-alat genital yang nyata., biasanya terjadi setelah 12 bulan atau lebih setelah menarke ( haid pertama). Rasa nyeri timbul sebelum atau bersama-sama dengan permulaan haid dan berlangsung beberapa jam, berupa kejang pada perut bagian bawah, yang dapat menyebar ke daerah pinggang dan paha. Gejala sistemik yang menyertai berupa mual, muntah, sakit kepala, diare dan sebagainya.

Banyak faktor penyebab terjadinya disminore primer, [10] menyebutkan bahwa penyebab dismenore primer antara lain: faktor kejiwaan dan faktor endokrin. Faktor kejiwaan yang sering terjadi disebabkan remaja tidak mendapat penjelasan yang baik tentang haid. Faktor endokrin yang paling menentukan adalah kontraksi uterus yang berlebihan, karena endometrium dalam fase sekresi, maka dihasilkan prostaglandin, yang menyebabkan kontraksi otot polos, jika prostaglandin berlebihan dilepaskan, maka selain dismenore dijumpai pula efek umum seperti muntah dan diare. Jadi pelepasan endometrium dihasilkan dari penebalan atau peradangan lapisan endometrium uterus dan prostaglandin dihasilkan sebagai bagian dari proses peradangan. Pelepasan endometrium dihambat oleh progesteron, tetapi distimulasi oleh estrogen. 
Nyeri Haid, Penyebab, dan Penanggulangannya..... (Kusmiyati)

Dismenore sekunder adalah dismenore yang terjadi karena keadaan patologi, misalnya pada wanita yang menderita endometritis. Rasa nyeri terjadi setiap kali haid, jenis nyeri ini memerlukan pemeriksaan. Penyebab nyeri ini antara lain rahim terbalik, sehingga darah haid tidak mudah dikeluarkan; adanya benjolan besar atau kecil di rahim, pemakaian spiral; infeksi pelvis dan endometriosis.

Beberapa orang kadang tidak dapat bangun dari tempat tidur karena nyeri haid yang dirasakannya, menurut [10] nyeri haid dibedakan menjadi:tiga yaitu a). nyeri haid ringan yaitu nyeri dengan rasa nyeri yang berlangsung beberapa saat, sehingga perlu istirahat untuk menghilangkan nyeri; Nyeri ini tidak mengganggu aktivitas harian dan tidak menyebar tetap berlokasi di perut bawah. b). nyeri haid sedang, memerlukan obat untuk menghilangkan rasa nyeri tanpa meninggalkan aktivitas sehari-hari. nyeri ini menyebar di bagian perut bawah; c). Nyeri haid berat, penderitanya memerlukan istirahat lama, akibatnya meninggalkan aktivitas sehari-hari selama satu hari atau lebih. Nyeri ini disertai dengan pusing, sakit kepala, muntah dan diare.

\subsection{Penanggulangan nyeri haid}

Penanggulangan nyeri haid dapat dilakukan dengan mengurangi atau menghambat stimulus nyeri, agar tidak sampai ke otak. Seperti dijelaskan di atas, nyeri haid terjadi karena peningkatan prostaglandin dalam darah yang merangsang peningkatan kontraksi uterus, sehingga terjadi penurunan aliran darah dan oksigen ke uterus yang mengakibatkan iskemia.

Impuls nyeri dapat diatur dan dihambat oleh mekanisme pertahanan di sepanjang sistem saraf pusat, impuls nyeri dihantarkan saat sebuah pertahanan di buka dan impuls dihambat saat pertahanan ditutup. Salah satu cara menutup pertahanan ini dengan merangsang sekresi endorfin yang akan menghambat pelepasan substansi nyeri (P). Tindakan apapun yang dilakukan dalam mengatasi nyeri bertujuan untuk mengurangi ketegangan uterus melalui mekanisme fisiologis, yaitu memperlancar pembuluh darah, menghambat sensasi nyeri dan memberikan kenyamanan pada individu.

Beberapa cara untuk mengurangi nyeri dapat dilakukan melalui tindakan farmakologis maupun non farmakologis [16]. Tindakan farmakologis meliputi: a) Sedatif, untuk mengurangi kecemasan dan merangsang untuk tidur; b).Analgesik, menghilangkan nyeri dengan mencegah impuls saraf ke otak, meliputi anti nyeri, relaksasi dan aktivitas rileks. [5] menambahkan, enkefalin dan endorfin merupakan zat yang berhubungan dengan pengaturan nyeri, berfungsi sebagai zat penghantar eksitasi yang mengaktivasi bagian sistem analgesik otak. Infus zat ini ke dalam cairan serebrospinalis ventrikularis ketiga dapat menyebabkan analgesia. Berdasarkan kedua pendapat tersebut, nyeri haid dapat dikurangi dengan obat anti peradangan atau obat-obat lain yang dapat menghambat biosintesis prostaglandin.

Tindakan non farmakologis, antara lain meliputi a). Masase, merupakan pijatan lembut pada bagian tubuh yang nyeri dengan menggunakan tangan. Teknik ini dapat merangsang tubuh melepaskan senyawa endorpin yang merupakan pereda sakit alami, sehingga akan menyebabkan relaksasi otot dan memberikan efek sedasi; b). Kompres panas, kata panas yang dimaksud di sini adalah kompres dengan air panas bersuhu $43-46^{\circ} \mathrm{C}$ [7] atau biasa disebut air hangat, yang selanjutnya dalam tulisan ini disebut kompres hangat. Kompres hangat dapat meningkatkan aliran darah, menurunkan ketegangan otot dan mengurangi nyeri akibat spasme atau kekakuan. c). Kompres dingin digunakan untuk membatasi akumulasi pada jaringan tubuh, mengurangi ketegangan otot, memperlambat transmisi nyeri dan impuls-impuls lainnya melalui neuron sensorik; d). teknik distraksi adalah teknik pengalihan dari fokus perhatian terhadap nyeri ke stimulus yang lain., teknik ini antara lain meliputi distraksi penglihatan (misalnya menonton televisi), pendengaran ( misalnya mendengarkan musik yang disukai ), pernafasan dan sebagainya, Seperti pendapat [5], nyeri dapat dialihkan dari satu permukaaan tubuh ke permukaan tubuh lainnya, tetapi yang lebih sering dimulai dalam salah satu organ visera di alihkan ke suatu daerah di permukaan tubuh. Nyeri bisa berasal dari satu visera dan dialihkan ke suatu daerah lain yang letaknya tidak tepat sama dengan daerah yang menyebabkan nyeri. Lebih lanjut dijelaskan, mekanisme nyeri alihan terjadi seperti pada Gambar 1, yang menunjukkan cabang-cabang serabut nyeri viseral bersinaps di dalam medula spinalis dengan beberapa neuron urutan kedua yang menerima serabut nyeri dari kulit. Apabila serabut nyeri viseral tersebut dirangsang kuat, sensasi nyeri dari visera menyebar ke dalam beberapa neuron yang biasanya menghantarkan sensasi hanya dari kulit, dan orang tersebut mempunyai perasaan bahwa sensasi itu benar-benar berasal dari dalam kulit.

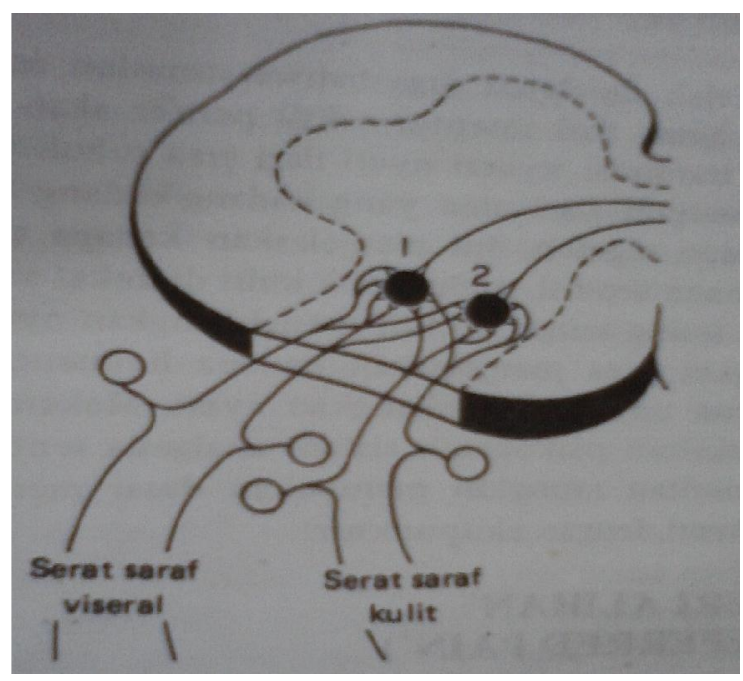

Gambar 2.1 Mekanisme nyeri alihan [ 5 ]

Kompres hangat memberikan efek terapi untuk mengurangi nyeri, antara lain: a). Meningkatkan permeabilitas kapiler; b). meningkatkan aliran darah; c). ketegangan otot menurun dan d). Metabolisme jaringan meningkat [13] Jadi dengan kompres hangat akan meningkatkan permeabilitas kapiler, yang berakibat meningkatkan pergerakan zat sisa dan nutrisi. Meningkatnya aliran darah akan meningkatkan pengiriman nutrisi dan membuang zat sisa, menurunnya ketegangan otot akan meningkatkan relaksasi otot dan mengurangi nyeri akibat kejang atau kekakuan. 
Mekanisme fisiologi dengan pemberian tindakan non farmakologis belum jelas, kemungkinan akan merangsang peningkatan endorfin yang memblokir lepasnya substansi nyeri dari neuron sensorik, sehingga menghambat penghantaran impuls nyeri ke lobus parietal dan sensasi nyeri berkurang. Seperti pendapat [17] yang menyebutkan bahwa signal dari reseptor nyeri mencapai interneuron di corda spinalis dan menginduksi pembebasan substansi $\mathrm{P}$ ( pain). Neurotransmitter ini akan mencapai daerah hipotalamus dan otak tengah, yang akan merangsang pembebasan endorphin dan enkephalins (suatu neuromodulator) sebagai pembunuh nyeri alami.

Berkaitan dengan penanggulangan nyeri haid cara non farmakologis, hasil penelitian [11], menyebutkan bahwa pemberian kompres hangat (dengan air bersuhu $44^{\circ} \mathrm{C}$ ) berpengaruh pada penurunan nyeri haid pada siswa MTs Darul Aitmal Jerowaru Lombok Timur. Kompres hangat yang diberikan pada daerah perut bagian bawah, kemungkinan memberikan relaksasi otot-otot, memperlebar pembuluh darah dan mengurangi nyeri akibat spasme atau kekakuan. Teknik distraksi berupa terapi musik telah dilakukan oleh [6] yang menyimpulkan bahwa ada pengaruh signifikan terapi musik mozart terhadap penurunan tingkat nyeri haid ( disminore) primer pada remaja usia 15-19 tahun. Musik mozart adalah jenis musik klasik [14]. Mendengarkan musik tempo lamban dapat memperlambat dan menyeimbangkan gelombang menuju ke otak yang menandakan ketenangan [3]. Kemungkinan kompres hangat dan musik mozart merangsang peningkatan endorfin yang memblokir lepasnya substansi nyeri dari neuron sensorik, sehingga menghambat penghantaran impuls nyeri ke lobus parietal dan sensasi nyeri berkurang.

Hasil penelitian lain yang berhubungan dengan penanggulangan nyeri pada organ reproduksi telah dilakukan oleh [15], yang menyimpulkan bahwa teknik relaksasi bernafas berpengaruh signifikan pada kemajuan persalinan. Kemungkinan yang terjadi pada hasil penelitian ini, relaksasi bernafas memberikan ketenangan dan rileks, sehingga otak akan mensekresi endorphin yang dapat mengurangi nyeri secara alami, yang disebabkan oleh kontraksi uterus. Berkurangnya nyeri, maka ibu merasa nyaman dan oksitosin juga akan disekresi untuk membantu kemajuan persalinan. Hal ini dipertegas oleh [4], yang menyatakan bahwa ibu yang dalam keadaan rileks dan tenang, maka oksitosin akan disekresi, sebaliknya jika ibu merasa cemas dan takut akan disekresi adrenalin yang akan menghambat pelepasan oksitosin. Terhambatnya pelepasan oksitosin, maka kemajuan persalinan akan terhambat.

Penelitian lain telah dilakukan oleh [8], yang menyimpulkan bahwa ada pengaruh signifikan pemberian kompres hangat $\left(45-46^{\circ} \mathrm{C}\right.$ ) terhadap pengurangan rasa nyeri persalinan.kala I fase aktif. Kemungkinan mekanisme yang terjadi sama seperti penjelasan sebelumnya, ketika terjadi kontraksi, maka otot uterus mengalami ketegangan. Pemberian kompres hangat akan menurunkan ketegangan otot uterus, sehingga ibu merasa rileks. Ketika ibu rileks dan nyaman tubuh akan mengalirkan endorphin. Seperti ditegaskan oleh [13] yang.menyatakan bahwa endorphin ( suatu medulator) sebagai pembunuh nyeri alami, yang disekresi oleh alur saraf desenden, akan menutup mekanisme pertahanan dengan menghambat perlepasan substansi P, sehingga mencegah stimulus nyeri dan sensasi nyeri berkurang.

Berdasar hasil penelitian tersebut, menunjukkan bahwa banyak cara untuk mengatasi nyeri haid, yang bertujuan untuk mengurangi bahkan untuk menghilangkan nyeri itu sendiri. Cara mana yang dipilih sangat tergantung pada kesenangan dan kenyamanan seseorang, misalnya ada orang yang senang dengan musik klasik, tetapi tidak dengan musik dangdut, sebaliknya ada orang yang suka mendengarkan musik dangdut, tetapi tidak suka musik klasik. Orang yang tidak suka musik dangdut, ketika diperdengarkan musik dangdut, tidak akan mengurangi rasa nyeri, yang ada malah menambah nyeri. Demikian juga dengan teknik yang lain, semua orang mempunyai respon sendiri-sendiri terhadap stimulus yang diberikan.

Stimulasi saraf sensorik dari reseptor taktil perifer akan mendepresi transmisi impuls nyeri dari area tubuh yang sama ataupun dari area yang kadang-kadang berjarak beberapa segmen [5]. Ini menjelaskan bahwa tindakan sederhana seperti menggosok kulit di dekat area yang nyeri sering berguna untuk menghilangkan nyeri. Hal ini pula yang dapat digunakan sebagai landasan untuk dilakukan beberapa terapi. Pijat misalnya, dilakukan untuk memeperlancar peredaran darah dan saraf, namun tidak semua orang dapat suka dipijat.

\section{KESIMPULAN}

Haid atau menstruasi merupakan peristiwa luruhnya dinding endometrium akibat penurunan kadar estrogen dan progesteron. Kejadian haid melibatkan ovarium dan uterus, dengan rata-rata panjang siklus haid 28 hari. Sebelum dan selama menstruasi sering terjadi nyeri di perut bagian bawah, yang disebabkan kontraksi dinding uterus dan sekresi prostaglandin yang berlebih. Nyeri haid dapat dikurangi dengan menghambat impuls saraf agar tidak sampai ke otak, antara lain dengan memberikan obat berupa analgesik atau obat anti peradangan atau obat lain yang menghambat biosintesis prostaglandin. Nyeri juga dapat dikurangi dengan memberikan terapi tanpa obat (non farmakologis) misalnya dengan masase, kompres hangat, kompres dingin, mendengarkan musik, menonton televisi atau melatih pernafasan.

\section{DAFTAR PUSTAKA}

[1] Andaners, 2010, Disminore (nyeri haid), http://Andaners, wordpress,com,

[2] Baried, A., 1993, Endokrinologi Ginekologi; Kelompok Studi Endokrinologi Reproduksi Indonesia, EGC, Jakarta

[3] Campbell, D., 2002, Efek mozart dan terapi musik dalam dunia kesehatan http:// astaqaliayah.com

[4] Chapman, 2006, Asuhan Kebidanan Persalinan dan Kelahiran, EGC, Jakarta

[5] Guyton, 1995, Fisiologi Manusia Mekanisme penyakit, EGC, Jakarta

[6] Hilmayani, 2011, Pengaruh terapi musik mozart terhadap tingkat nyeri haid ( dismenore) primer pada remaja usia 15-19 tahun di desa Tembeng 
Putik kecamatan Wanasaba Lombok Timur (Skripsi), STIKES Mataram

[7] Hidayat, A.A, 2006, Pengantar Kebutuhan Dasar Manusia, Aplikasi konsep dan proses keperawatan, Salemba medika, Jakarta.

[8] Khaer, Z, 2011, Pengaruh Pemberiaa Kompres hangat Terhadap Pengurangan Rasa Nyeri Persalinan Kala I fase aktif pada Primipara di Wilayah kerja Puskesmas Kerongkong Kecamatan Suralaga Lombok Tengah ( Skripsi) STIKES Mataram

[9] Lusa, 2009, Dismenore-dysmenorrhea, http://www.lusa.web.id.

[10] Mansjoer, 2000, Kapita Selekta Kedokteran, Media Aesculapius FKUI, Jakarta

[11] Maryani S., 2010, Pengaruh pemberian kompres hangat terhadap penurunan nyeri haid di MTs Darul Aitmal Jerowaru Lombok Timur (Skripsi) STIKES Mataram

[12] Nadiana, 2010, Siklus menstruasi pada wanita remaja , http:/repository.usus.ac.id/ bitstseam

[13] Potter \& Perry, 2005, Buku Ajar Fundamental Keperawatan Konsep Proses dan Praktik, EGC, Jakarta

[14] Qittun, 2008, Konsep dasar menstruasi, http://qittun.blogspot.com/2008/11

[15 ] Sulistia, R, 2011, Pengaruh teknik relaksasi bernafas terhadap kemajuan persalinan pada ibu Primipara Kala I fase aktif di ruang bersalin RSUD Praya Lombok Tengah ( Skripsi) STIKES Mataram

[16] Sylvia, Price \& Wilson, L.M. 2005, Patofisiologi Konsep Klinis Proses penyakit, EGC, Jakarta

[17] Starr and Taggart, 2001, Animal Structure and Function, Brooks/Cole, Australia

[18] Tamsuri,A., 2007, Konsep dan Penatalaksanaan Nyeri, EGC, Jakarta 